\section{CONNECTING A VIRTUAL PRODUCTION AND A PLC}

JAN KUBR, KONSTANTIN NOVIKOV, PETR HOREJSI, JANA
KLEINOVA, DAVID KRAKORA

Faculty of Mechanical Engineering, Department of Industrial Engineering and Management, University of West Bohemia, Pilsen, Czech Republic

DOI: 10.17973/MMSJ.2021_6_2021007

kubrj@kpv.zcu.cz society is considered to be between 5 and 7 percent [Halbrstat, 2018]. For these companies, this means there is a need to fill vacancies, which entails costs. Although these are difficult to quantify, a significant part of them are the costs of training a new employee [Urban, 2004]. The severity of this problem is underlined by a theoretical study [Stratman et al., 2004], which simulates companies with different product complexities and different proportions of permanent and temporary employees. It shows up to $25 \%$ higher production costs and up to 10 times higher quality costs in a hypothetical comparison of a company employing $100 \%$ permanent and $100 \%$ temporary labour. The same problem in employee training is pointed out in other studies, e.g. [Carlson et al., 2015].
This article deals with the implementation of virtual manuals for mass production workplaces in the automotive industry. The aim is to conduct a pilot study as a source for future research and the possibility of connecting virtual instruction manuals to production systems. A system was designed that uses its own software solution for creating instructions, which was connected to a PLC (Programmable Logic Controller) in a manufacturing company. The whole system is connected to the company's production cycle. This solution has been validated. Three months after the introduction of the innovation, it can be stated that during the application of the system, the scrap rate was reduced from an initial 12 pieces to a final state of 3 pieces, and the length of time for training newly arrived operators was shortened. The analysis focused mainly on the evaluation of scrap, the aspect of time in this case did not need to be stated due to the high workplace cycle. The proposed solution thus contributed to the streamlining and modernization of production and will be an important input for the creation of a general loT methodology.

KEYWORDS VR, Virtual Reality, PLC, Internet of Things, Work Instructions, Visualisation

\section{INTRODUCTION}

Nowadays, when great emphasis is placed on the speed and quality of product execution, virtual reality (VR) and its modifications, such as virtual instruction, have much greater potential. As studies show [Guo et al., 2020] [Abidi et al., 2019] [Patle et al., 2019], most of the potential of VR in industry lies in its use in assembly instructions. A number of studies point to the suitability of using VR for educational purposes - an example of a comprehensive view is presented by the systematic review [ Radianti et al., 2020]. The benefit of virtual assembly instructions is the enrichment of the work process with a clear animated image of the required operation. This can be especially useful for new employees and wherever employee rotation is used. At present, unemployment in the EU is relatively low (unemployment is only $8.3 \%$ as of September 2020, despite the Covid-19 pandemic [EUROSTAT, b.r.]), and industrial enterprises in particular are facing labour shortages at all levels. As some companies start to motivate their new employees by offering them special benefits, it often results in frequent job switching by employees between companies. Related to this is the rate of fluctuation, which averages between 14 and 16 percent, however, a healthy fluctuation in
One study [Horejsi, 2019] showed that thanks to the use of virtual reality, it is possible to reduce the training time of new employees by up to 30 percent. Similar results were shown by an older study [Horejsi, 2015] conducted at the same workplace using augmented reality.

So far, VR is used in large companies, where more complex products are manufactured or assembled, and emphasis is placed on the speed and accuracy of production.

This article describes a completely new approach to presenting virtual production manuals. The aim of the research is to find a general methodology for the presentation of virtual production instructions within the production line cycle using the concept of the Internet of Things. This article describes a pilot reference study, which was carried out in a manufacturing company - the implementation of a system for the presentation of production instructions within PLC control. In this sense, virtual instructions are not a continuous film or a sequence of images, but a visualization of work in real time. Thus, the virtual manual can be displayed directly during production and adapted to the production cycle. To synchronize the production manual with the workplace cycle, it is necessary to synchronize the manual with the production equipment or its parts.

It is possible to use a PLC (Programmable Logic Controller) to connect between the machine and its states. This device collects data or gives a signal to the machine to perform a certain activity. At the same time, it can be used as a bridge to connect the machine with "Smart Production", where it serves as a carrier of this data and is thus the best choice for future automation of production. [Chen et al., 2017]

However, the information provided by these sensors is still underused. Extraction of information from raw data generated by the sensors is a complex task, which is why solutions such as SDAEM (Sensor Data Analysis for Equipment Monitoring) are being developed - which has three main goals: data mining, interpretation of correlated data from sensors and adjustment of setpoints. This model has been used to monitor oil refining facilities in Brazil [Garcia et al., 2011].

Data from the PLC can also be transferred to virtual reality. Such an experiment was performed in Remote Access Laboratories (RAL), which are used to perform experiments on physical hardware using the Internet environment. Students set an elevator speed for optimal stopping of an elevator at a 
defined floor. Monitoring was performed on a 3D model built from LEGO $^{\circledR}$ and PLCs were used to evaluate the device. These devices used colour coding to indicate the speed of the elevator in the 3D model. An additional Arduino device later provided data from the sensors to the client [Maiti et al. 2019].

\section{REFERENCE CASE STUDIES}

Previous studies [Horejsi, 2015] [Horejsi, 2019] have shown the importance and usefulness of using virtual manuals in industrial practice. The research team will also try to create a uniform methodology for the implementation of effective production instructions depending on various input factors (factual, temporal and spatial characteristics of the process [Novikov, 2019]).

This paper also contains a proof-of-concept study, which expands the input variants of the technical implementation of the manual by the possibility of displaying virtual production manuals created in proprietary CAl (Computer Aided Instruction) software (described in the studies mentioned above) and displayed in a time cycle using sensors and PLC control. Next, the pilot deployment will be described and evaluated. As part of this pilot deployment, a variant of standard control of the manual using software and hardware buttons was also considered. Furthermore, the reasons why the "conventional" solution proved to be unsuitable in the case of the reference workplace will be explained. Generalization and incorporation into the concept of the methodology is then the next research task. Therefore, this paper describes the application of existing solutions in a new context.

\section{ANALYSIS}

As part of the pilot project, a workplace was selected where the production of parts for leading car brands, such as Audi or BMW, takes place. The workplace - for the pressing of nuts was deliberately chosen because it is a workplace with high staff turnover, slow staff training, high error rate and at the same time its process concept is neither trivial nor too complex (see below). At the same time, this workplace is equipped with sensors that will help in the presentation of instructions in the cycle. This workplace is divided into two subgroups: Setting up parts and Pressing control. Each of these workplaces is operated by a different employee and each of them performs a different type of job. The main part of this work space is the nut press into which the part is inserted, and on the other side of the workplace it is removed (see Figure 1).

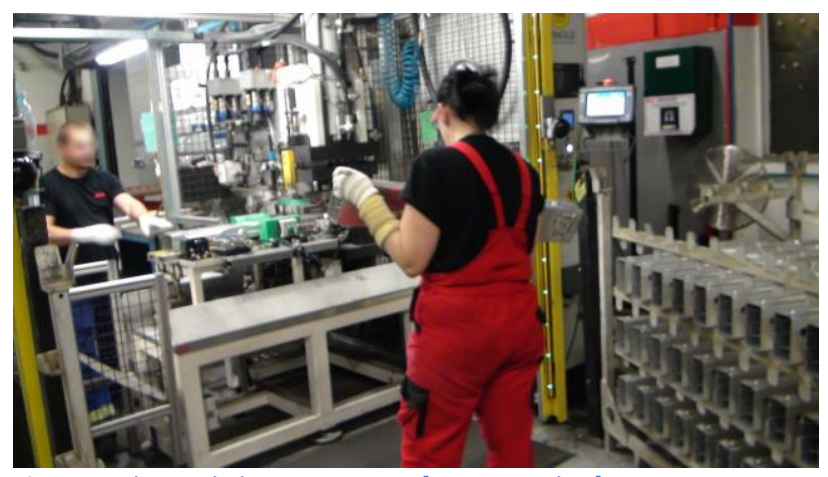

Figure 1. The workplace - nut press [source: author]
In order to create and implement the manual, it is necessary to perform several analyses, which will be described below. These analyses will help to understand the whole process and describe the individual items that are needed to create the instructions.

It will be based on the methodology proposed in [Horejsi, 2019], and this methodology has been tested on real projects in various types of production.

\subsection{Process analysis}

The aim of the process analysis was to find out and map the current state of the whole process and to find out the work procedure at individual workplaces and work with them. For the process analysis, the nut pressing workplace was divided into two parts:

- $\quad$ Setting up the part in the nut press (Figure 2)

- Control and removal from the nut press (Figure 3)

Set up of nut press

The workflow of this part of the process is:

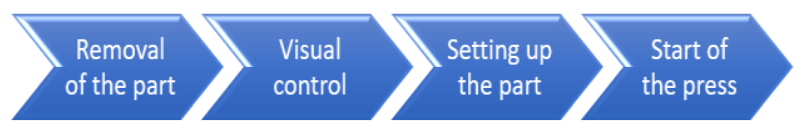

Figure 2 Process - setting up the nut press [source: author]

\section{Removal of the part}

The aluminium part is taken from the stands prepared by the manipulators for the workplace. They ensure a continuous supply of material to the workplace. Parts can be removed from two stands - right/left. This ensures the smooth operation of the machine. In each stand there are 48 parts in 4 tiers.

\section{Visual inspection}

After removing the part from the stand, it is important to visually inspect the locations which are marked as problematic. These are mainly welds. These welds are located on all four sides, so the part must be rotated to visually inspect it from all sides.

\section{Setting up the part}

The inspected part must then be placed in the jig in the pressing machine itself. For correct insertion, special elements are placed on the pressing machine, which indicate where the part is to be placed. However, it is necessary to pay increased attention to which side the part is inserted into the nut press. After the part has been correctly placed on the rollers, the part is pushed onto a special centering mandrel. After reaching the mandrel, it is necessary to pull the part by hand from the centre outwards towards the operator to ensure the part puller is properly attached. 


\section{Start of the press}

After the correct insertion of the part, the operator steps back from the press machine and presses the button to enter the signal to start pressing. Stepping back from the press machine is also monitored by a light gate for safety reasons, which prevents accidents. Start buttons are located on each side of the workplace for both variants of material removal (right/left). Pressing the button is also a signal to end the whole process at this workplace and the operator starts the cycle over from the beginning.

\section{Control and removal from the nut press}

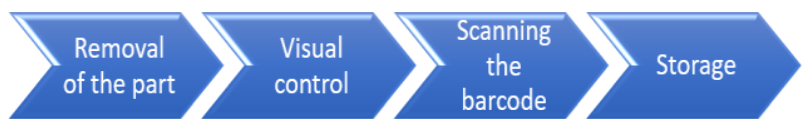

Figure 3 Process - inspection and removal from the nut press [source: author]

The workflow of this section is:

\section{Removal of the part}

After pressing, which is performed by the machine, it is necessary to remove the part from the nut press. The removal instruction is a green light on the screen above the cage entrance. This part of the process is controlled by light gates, which are located before the entrance to the cage. If you enter the zone at a time not intended for removing the part, a red light will appear, a warning signal will sound and the machine will stop.

\section{Visual Inspection}

After removal, the part needs to be visually inspected, especially the problematic parts, which include the correct pressing of the nuts and the inspection of burns. In order to be able to check these parts, it is necessary to rotate the part and check it from several points of view, so that any defects can be detected. If a defect is found on the part, it is possible to eliminate it at the workplace using simple tools (cleaning with a brush) or by handing it over for repair to the workplace assigned to it.

\section{Scanning the barcode}

The next step is to rotate the part under a special code reader located on the table next to the nut press cage. Reading the code from the part is used for possible future detection of an error from a series of products. The part is inserted under the scanner/reader and the embossed code is read. Care must be taken to ensure that the code from the part is actually read, and therefore to insert the part with the embossed code side.

\section{Storage}

The next step is to remove the part from the reader and then place it in the prepared box. Two boxes are ready to ensure the smooth running of the whole process. In each box, there are plastic jigs in which the part is stored. The part needs to be stored properly. Seven parts can fit on one level of the box, while three layers are stacked in one box. The box is then closed by the operator and taken to an intermediate warehouse, where it is ready for dispatch.

\subsection{Time analysis}

Another important part of the overall analysis is the time analysis. In this analysis, the activities of individual steps were used which must be performed to complete the process. Furthermore, it was necessary to arrange these activities in a continuous sequence. For this whole process, 15 measurements were determined for each part of the workplace (Parts set up/Parts inspection). This analysis will be used to assess what cycles are used in the workplace and what type of instructions will be suitable for the production.

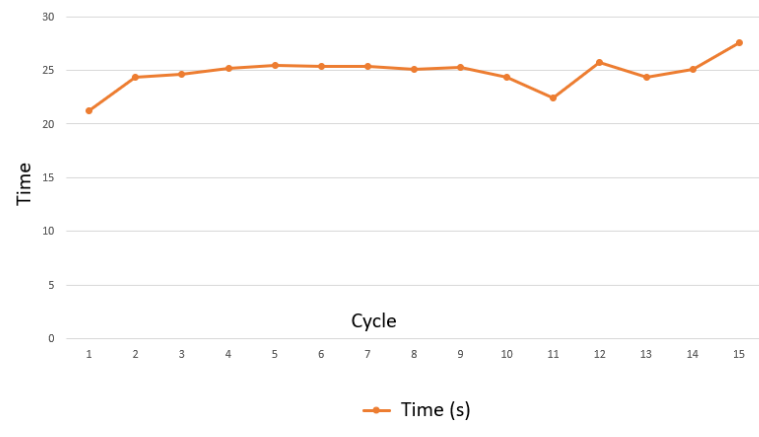

Figure 3. Time analysis for workplace: Set up of parts [source: author]

From the measurements (see Figures 4 and 5), it follows that the maximum clock cycle of the Parts set up at the workplace is approximately 25 seconds. With regard to the duration of the production cycle, the variant of manual control of the manual by the operator was excluded - manual control could increase time disproportionately to the duration. Therefore, it was necessary to create a manual with automatic synchronization of steps.

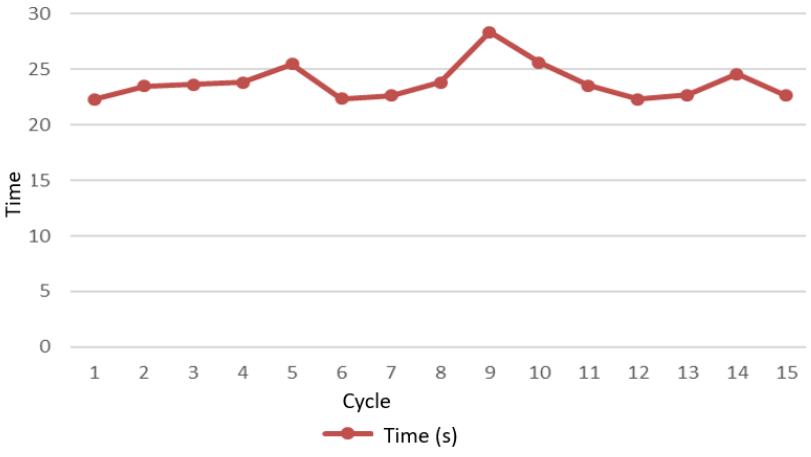

Figure 5. Time analysis for workplace: Inspection of parts [source: author]

The time analysis found that the inspection workplace is operated at a cycle not exceeding 26 seconds. The deviation of the $9^{\text {th }}$ cycle was caused by the fact that the operator was preparing the box that is used for product's expedition. The preparation of the box is thus the only point in the work procedure that would be appropriate to eliminate in order to improve the process. The speed of the cycle means that it will not be possible to implement the manual control via buttons, as this activity would delay the operator.

\subsection{Analysis of input data}

Correctly processed and modified $3 \mathrm{D}$ models are required to create instructions within the CAI itself, which uses Unity 3D software. The company provided CAD data only for the engine beam. However, this data was unnecessarily extensive, and therefore it was necessary to reduce the parts that are not used 
in the manual. Another problem was the format in which this CAD model was received (see Figure 6). It was a .CATPart format. This type of model was created directly by the manufacturer in the Catia V5 program from Dassault System. A classroom at the Department of Machine Design at the Faculty of Mechanical Engineering was used to modify the model in this program. In the program, redundant parts were removed from the model, such as sketches, elements describing the individual components of the model and especially elements that were not needed for further creation of the manual. To insert a model directly into Unity 3D, it was necessary to save this model in another format. The best choice for saving it is the .STEP format, which can be inserted, for example, into the 3DS Max program. This step must be saved in .fbx format, which can be inserted and further worked with directly in Unity3D.

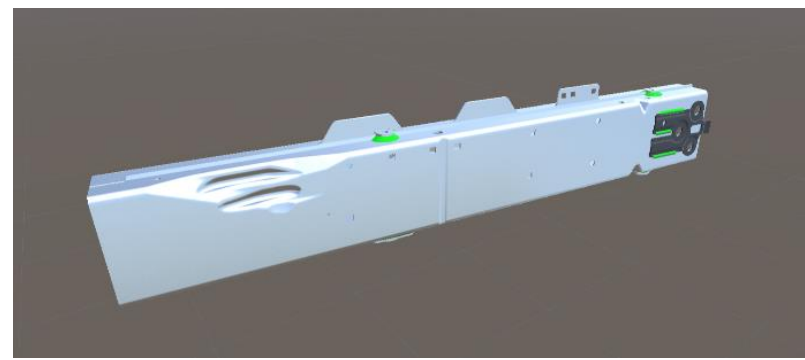

Figure 4. Part after custom modification [source: author]

A model of the entire workplace (see Figure7) was also needed to create a complete virtual manual. As this workplace model was not provided by the contracting party, it had to be created in modelling software. In order for the model to correspond to the real environment, it was necessary to measure the entire workplace and draw it up in detail. Great emphasis on accuracy and quality was placed especially on the part of the workplace where the nut pressing centre itself is located. The degree of quality of execution of this part greatly helps the better orientation within the workplace and the correct handling of components. The workplace was modelled in SolidWorks and the basic materials were added in 3DS Max, from which it was then possible to insert individual elements directly into Unity 3D.

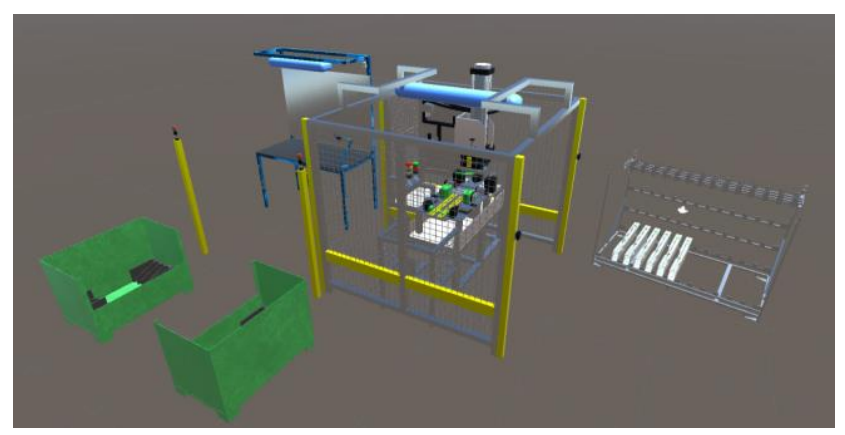

Figure 5. The nut press workspace created in Unity3D [source: author]

\subsection{Spatial analysis}

Spatial analysis is an important part of these analyses. this analysis determined the layout of the entire workplace, as shown in Figure 8. Furthermore, the movement of individual operators around the workplace was recorded.

\section{Workplace layout}

The graphical representation of the workplace layout indicates whether the production facilities are used efficiently, whether the production capacities of the company are sufficient or whether this production system would be able to handle the increase in production volume or a change in the production programme.

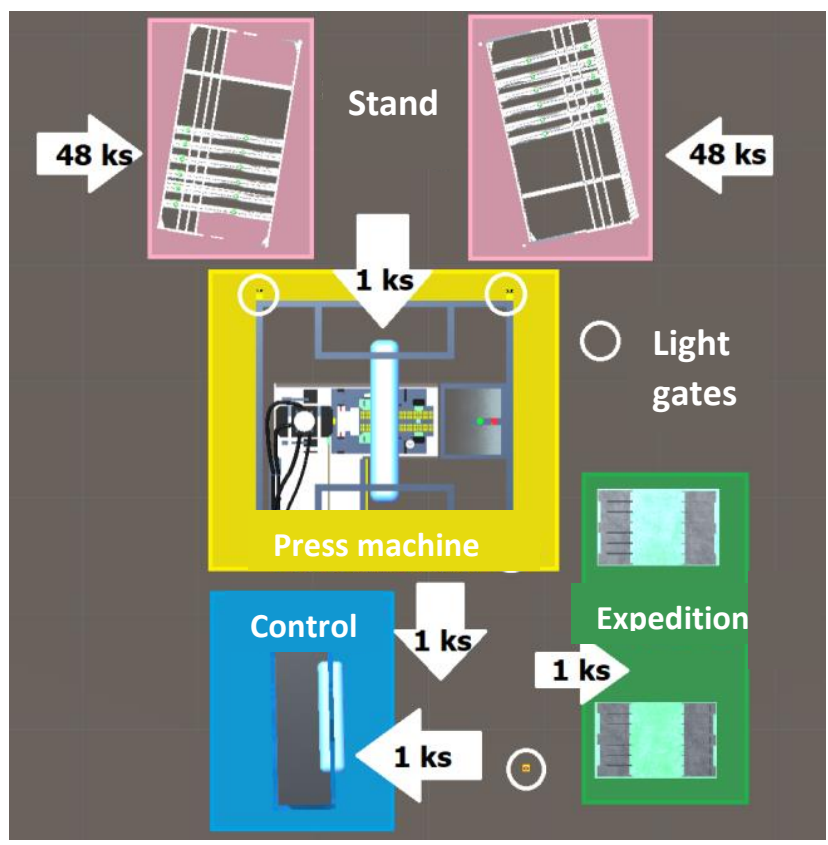

Figure 6. Workplace layout [source: author]

The position of individual elements in the layout is determined by predefined positions, which are marked in place. The task of this work is not to improve the spatial arrangement of the workplace, it is included for a better understanding and orientation of the workplace. It can be seen from the material flow that 48 pieces of beams in racks are brought to the workplace, from which the individual parts are removed and inserted into the pressing machine. The piece is then removed from the pressing machine, inspected and, after reading the code, stored in shipping crates.

\section{Spaghetti diagram}

This diagram (see Figure 9) shows the extent to which the operator moves in a given workplace. It is possible to read from the diagram whether the operator is performing unnecessary movements and slowing down the whole process. The results of this diagram are important for determining the hardware that is going to be used for displaying virtual instructions. It will help to determine if a static monitor can be used or if the solution must be mobile. 


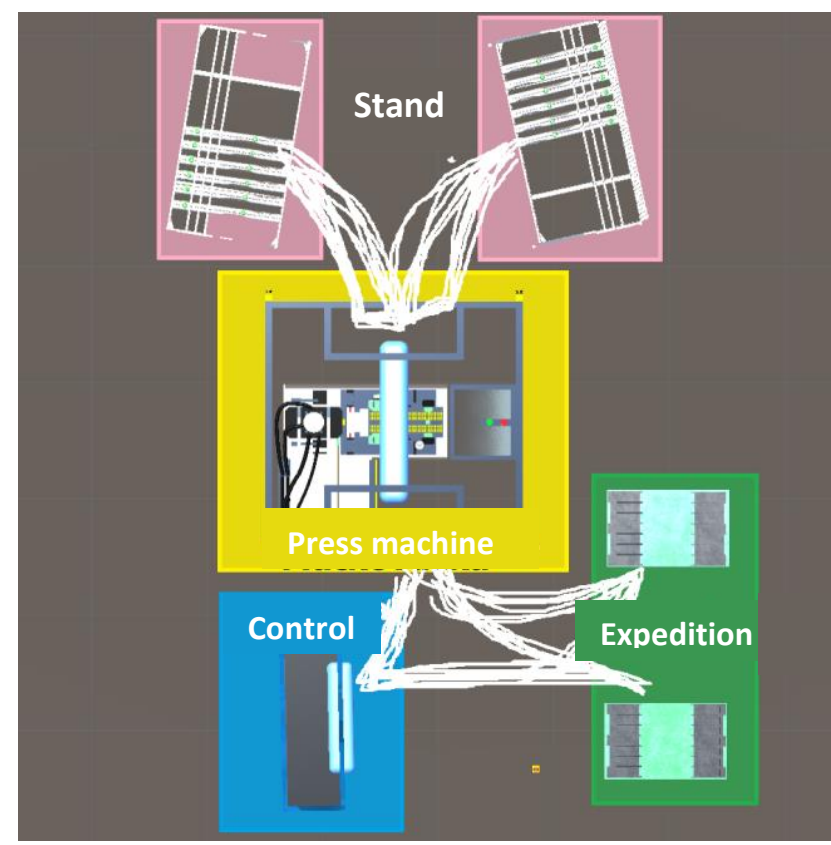

Figure 7. Spaghetti diagram [source: author]

\section{Field of vision}

The field of view at the workplace determines whether it will be possible to see the virtual instructions while working. It will also significantly affect the selection of the hardware.

\section{IMPLEMENTATION}

The overall implementation of the manuals was divided into three subchapters: Processing of the Virtual Manual, Linking of the Manual, and Display Hardware. The individual steps follow each other and together they provide a clear guide on how to proceed with the actual implementation of the guide from its establishment to installation at the workplace. In the chapters below, the author uses the knowledge gained in solving previous projects.

\subsection{Processing of the Virtual Manual}

The processing of the entire manual was processed in our own CAI and Unity 3D program.

The models are the basis for creating the instruction manuals themselves. In the previous section, it was mentioned that the actual model of the workplace had to be created, mainly with emphasis on the detail of the design, especially in the part of the pressing machine, where there is a high level of risk when inserting the part. The main component, i.e. the stand for the engine part, was provided by the contracting party. However, this model had to be modified.

After setting up and inserting the models into Unity3D, it was necessary to prepare the scene to match reality. Thanks to the spatial analysis, in which all the dimensions of the workplace are recorded, it was possible to set all the distances of the stands from the press machine, the distance of the code reader, which is located on the auxiliary table at the press machine, and the distance of the shipping boxes according to precisely determined positions.

Another procedure was to design a suitable UI (user interface) as shown on Figure 10, i.e. the visual side of the entire virtual manual. It was necessary to enlarge all the text fields so that they could be read from a certain distance. The shade of light grey was chosen as the background, on which all the components of the manual stood out the most. The buttons for possible step control were also enlarged. This modification thus changed the entire visual appearance of the virtual manual.

From the process analysis, it was found that it is necessary to create two separate manuals for each workplace, as the workplaces are serviced by separate staff. The workflow (at both workplaces) consists of four steps. The number of main animated steps in the guide must correspond to this. In certain steps, hazardous (danger area) activities are encountered. Such activities need to be highlighted and pointed out in the manual using simple standardized symbols. These symbols clearly warn the user that in a given step they should pay increased attention to the work performed. The symbols were chosen to be simple and specific to the activity performed, among other things due to some employees speaking foreign languages.

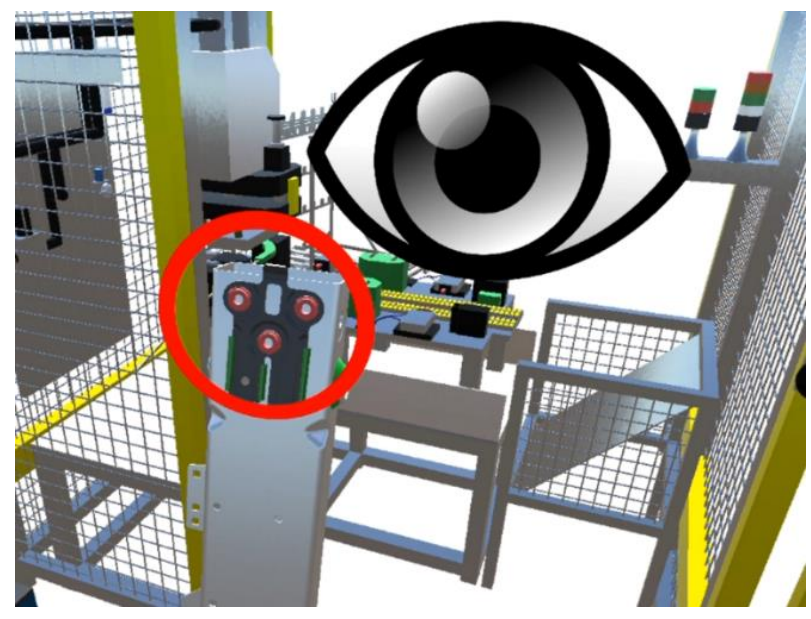

Figure 8. Symbol showing danger area [source: author]

Another necessary element based on the process analysis was the addition of step numbering in the cycle and a brief description. This helps the employee to quickly find out which step of the workflow they are currently in and which step follows.

From time analyses at both workplaces, it was found that the clock speed of both workplaces is too high, which means that it will not be possible to use stepping buttons. To set up the virtual manual, however, this means that the manual cannot be divided into animated steps, but only into one step, which contains individual animations. This measure ensures that the manual runs in one step in a loop. However, it is important to set the times of the individual animations according to the real procedure, so that they correspond to reality. The maximum possible deviation was \pm 1 second.

Before the final deployment of the manual into live operation, a group of experts was consulted. The output of the consultation was the addition of other visual elements for simple and clear orientation of operators in the production process. 


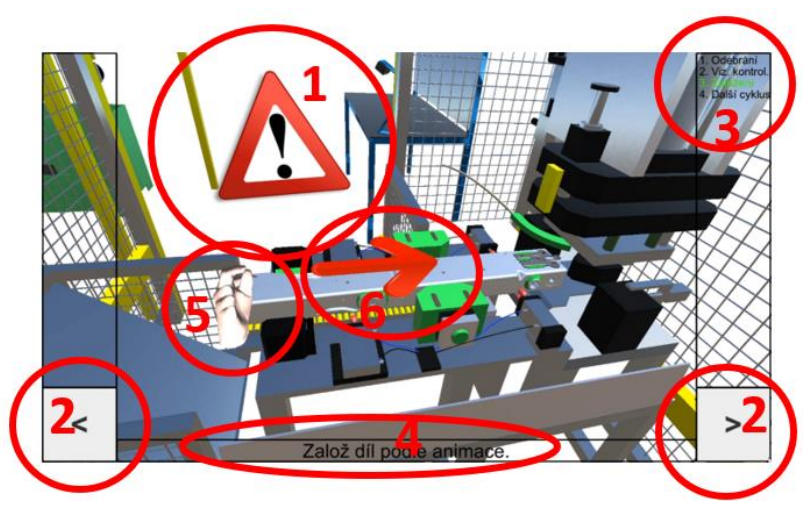

Figure 9. Final appearance of the manual [source: author]

Description of the individual symbols used (Figure 11).

1. Symbol for the occurrence of a possible risk

2. Step buttons, reverse/forward step selection

3. The order of individual steps in the process

4. Additional information to the current animation

5. Hand symbol to help quickly determine the pull of the part

6. Symbol determining the object's direction of movement

\subsection{Synchronization of the Manual}

The time analysis found that it would not be possible to control the manual using the buttons on the display or the added hardware button. With such a high cycle, this would slow down the whole process and thus lead to lower productivity. As a result, the manual will need to be controlled automatically.

After a thorough analysis of the process and of the entire workplace, the following procedure was proposed to obtain a signal which starts the virtual instructions automatically

\section{Input signals}

\section{Workplace: Setup of parts}

The operator at the Setup of parts workplace must press the button located on the machine cage (right/left side of the cage depending on which side they are currently removing the part from) at the end of each cycle. This button signals the machine using a programmable logic controller (PLC), and instructs the operator to start pressing the nut. It is this signal that determines the start of the virtual instruction manual.

\section{Workplace: Pressing control}

At the Pressing control workplace, the operator does not use a button to start another pressing cycle. The operator only passes through the light gates, which check whether they are not entering the machine at the wrong time. The starting point in this process, however, is the completion of the pressing. The fact that the pressing has been completed is a clear signal to start the manual from the beginning.

A problem occurred while trying to collect data from the PLC. After consultation with experts dealing with the setup of the machines in the company, it was clear that reprogramming the PLC is not possible, as it is protected by the company's headquarters. Such an intervention could disrupt the operation of the entire machine and change the individual cycles of the process. The big question was how to get the transmitted signal from the buttons or the machine. [Blazek, 2013]

\section{Hardware options for data collection}

There are several devices for collecting data of this type. For this variant, three were selected, which are described below in Table 4-1, and the best choice was selected using the decision table, which was compiled by the author.

In the next step, it was necessary to select a suitable device.

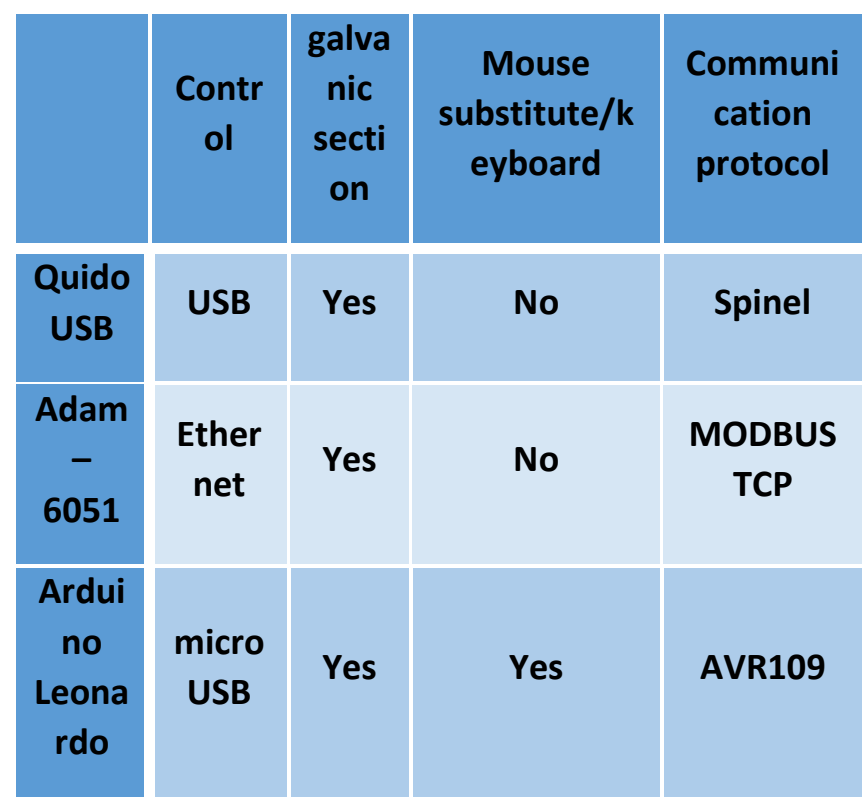

Table 4-1 Comparison of modules [source: author]

Table 1 compares the key features needed for implementation.

1. Control: Ethernet connection via network/connection via USB/microUSB directly to PC

2. Galvanic separation: separates two or more parts of the circuit so that they are not connected by a conductor, but at the same time allows the passage of electrical energy

3. Mouse/keyboard substitution: a simple feature where the operator can simulate mouse or keyboard functions

\section{Communication protocol}

The most important selection factors include control and the ability to replace the mouse/keyboard. These points are best met by the Arduino Leonardo, which can convert the signal at the input to a fictitious keystroke at the right of the output, i.e. to the control PC directly using a microUSB/USB connection cable. This significantly helped in deciding which module to use.

However, since the Arduino Leonardo is not equipped with galvanic isolation, such a measure had to be adjusted. It was necessary to add an electric capacitor and a ceramic carbon resistor, to the connection plate. These components helped 
with galvanic insulation and thus provided a secure connection to live operation.

The core and the main part of Arduino's functionality is its coding. Arduino (see Figure 12) can be programmed using $\mathrm{C}++$ or the Wiring library. This code is written in an environment called Arduino Ide, which is free to download from the Arduino website.

A program was created (similar to the one described above) that monitors the status of the input pin. Such a signal is the pressing/touching of a button or the completion of the pressing machine's operation. After this signal, the Arduino "sends" a right arrow signal, which starts the instruction step from the beginning. Time synchronization means the sequence of the instructions corresponds to the real process. After testing the application, protection against double-clicking had to be added to the code. Such a problem could occur if the site operator accidentally pressed the signal button twice in a row. This problem was solved by adding a delay after receiving the pin - it was set to $1000 \mathrm{~ms}$, which safely protects the "double-click". In order for the Arduino to be installed directly at the workplace, it had to be placed in an industrial box with a DIN rail for direct placement in the distribution box, which is located next to the machine.

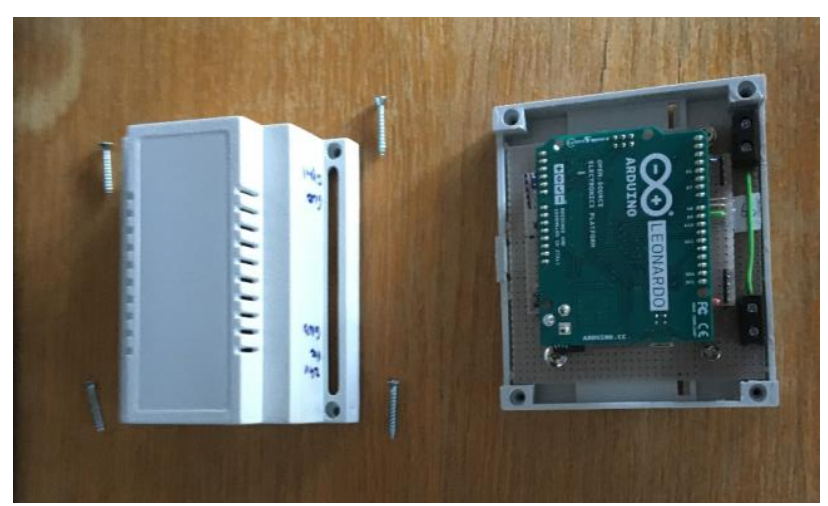

Figure 10. Arduino in a box on the DIN ledge [source: author]

\subsection{Imaging devices}

The procedural and spatial analyses found that the workplace is divided into two separate parts, which are each operated by one employee. The view of the operators (during the main activity) is facing each other. Therefore, this analysis showed that two monitors will be needed, which will be separate and directed towards a specific operator.

The input for choosing the right hardware was spatial analysis. First, it was necessary to choose the correct location of the monitors. The starting point for the correct placement of the monitors was the determination of the field of view of the operators.

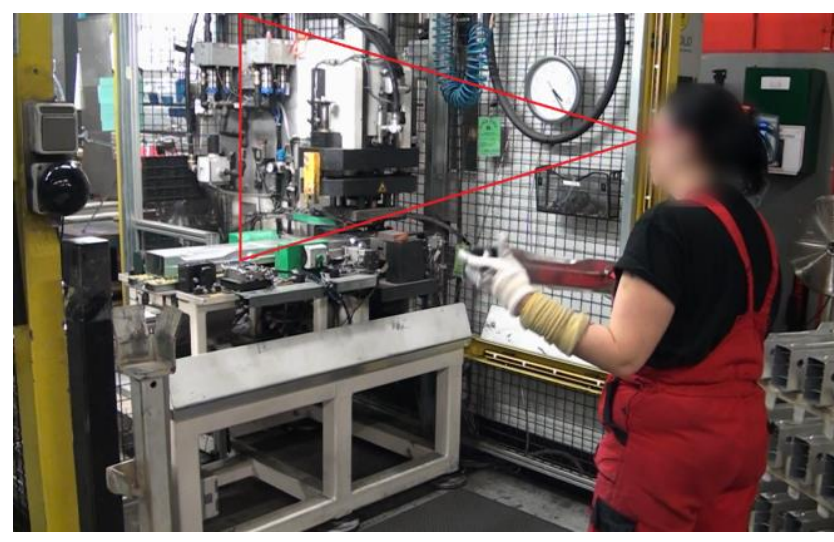

Figure 11. Operator's field of view [source: author]

Figure 13 shows the operator's field of view and the position from which the monitor can be seen. The field of view of the operators at both workplaces is approximately the same. This made it possible to place both monitors inside the cage. The monitors were placed back to back using a simple profile and a monitor holder. These monitors also do not interfere with the work. As the operator did not move more than 3 metres from the workplace, 21 " monitors were chosen.

It was necessary to solve the location of the computer, which could be implemented in two variants:

\section{a) Placement directly by the monitors}

This option would be simpler in terms of cabling - long cables would not be needed and the connection would be closer to the monitor. However, the disadvantage of this variant is that the PC is located directly in the cage of the machine, so the computer could overheat. Another indisputable disadvantage is accessibility for servicing. If the computer needed to be reset or maintained in any way, the production process would need to be interrupted.

\section{b) Placement near the machine}

Variant b) is farther away from the monitors, but in contrast to variant a) the computer is stored in a box next to the machine cage, where the temperature is much lower which means there is less possibility of overheating. Probably the biggest advantage, however, is that it is possible to access the computer while the machine is running.

Both variants were discussed with company representatives. Variant b) was chosen as the final one, where the possibility of computer maintenance during the operation of the machine played a major role.

Once the location of the PC in a special "tin box" (measuring

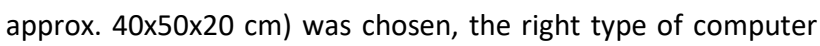
(able to fit in that space) had to be selected. Finally, we chose a DELL OptiPlex MFF 3070. This computer meets the graphics, processor and dimensional requirements. After selecting the PC, it was possible to create the .exe file type. Therefore, the application was created for a 64-bit operating system.

The last requirement was the type of connection between the PC and the monitor and the Arduino. A standard HDMI cable with a length of 5 metres was chosen to connect the PC and the 
monitor. A cable with USB (PC)/microUSB (Arduino) terminals was selected to connect the Arduino to the PC.

The pictures below show the final state of the entire workplace equipped with monitors and functional instructions. Figure 14 shows how the Arduino, with the DIN rail mounting box, was placed in the distribution box.
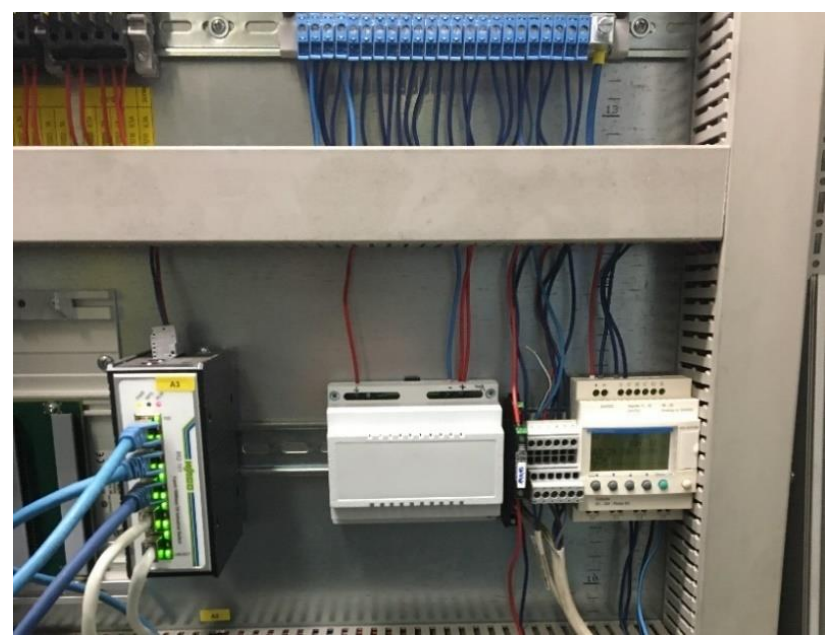

Figure 12 Arduino in distribution box [source: author]

Figure 15 shows a workplace equipped with a monitor projecting instructions for the workplace.

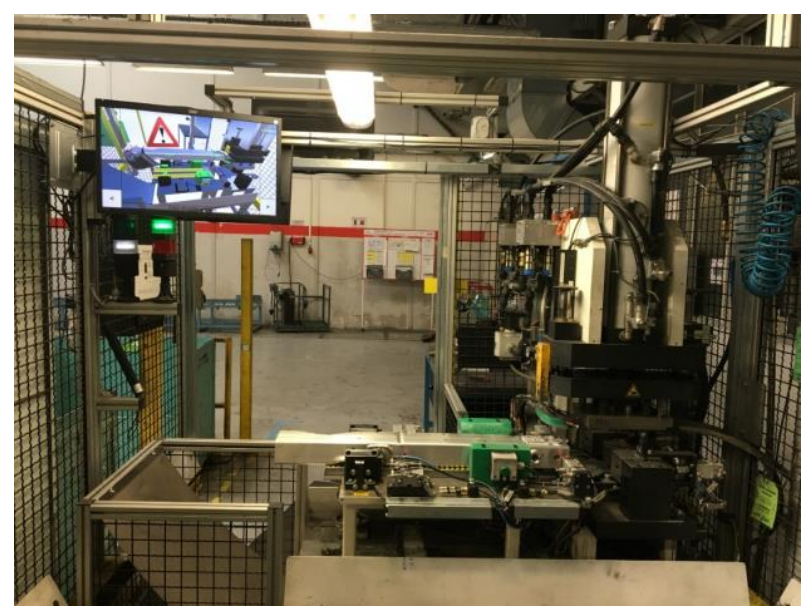

Figure 13 Monitor with Manual at workplace [source: author]

\section{RESULTS AND DISCUSSION}

The use of sensors for data collection is one way to find out the status of a device. A possible use is to monitor data to evaluate the condition of the motors on a conveyor in real time [Kiangala and Wang, 2018]. This data can predict the possibility of equipment error and thus prevent losses. Such a solution is generally needed to reduce possible defects.

Another possible solution for reducing the error rate is to use production instructions. Combined with the connection to the machine's sensors, this solution was able to reduce this value at a selected site, which was analysed for nine months using error records, with a baseline of 12.2 scraps with a deviation of 1.1 scraps. After the implementation of the solution, the state of the system changed to 3.2 scraps with a deviation of 0.4 . (Values are related to the first half of a production shift of an operator). This measurement was performed for 3 months. The high number of scraps in the initial state was mainly influenced by the misunderstanding of the elementary actions needed for the process. This factor is mainly influenced by high turnover in the workplace and a large language barrier. All these problems were solved mainly thanks to significant elements of visual management in the production manual. The fact that the entire manual is animated and, in particular, no further operation is required (automatic synchronization with the machine), was very positively welcomed at the workplaces.

This type of manual is especially suitable for training operators in this workplace. Even though there is a very high cycle at the workplace, the operator can master the entire process in about one production shift. For further applications, it is used by the operator for reassurance in unusual situations (e.g. a different type of defect). As mentioned above, this was a pilot project. The main goal was to test the functionality of connecting production instructions with a workstation without additional control options. After thorough testing, this type of device was ready for use with 5 other devices.

\section{CONCLUSIONS}

After selecting the appropriate hardware, it was necessary to install it at the workplace. This was done under the supervision of responsible persons. The Arduino was placed in a control cabinet using a DIN rail (see Figure 14) and connected to a PC using a USB cable. The Dell Mini was placed in a box next to the machine cage. The monitors were placed in the cage of the machine and each monitor was connected to the PC using an HDMI cable.

The virtual manuals themselves could be uploaded to the PC. Before live operation, the manual was tested and several problems appeared.

Both instructions were displayed on one monitor. This was because the PC did not recognize the second monitor. This problem was solved by using a suitable batch file to run on the PC.

Another problem occurred with the manual for checking the pressing machine. The problem was that the machine did not switch on the manual at the required time. This was caused by the use of Arduino reserved variable names. After eliminating these minor errors, the manual was ready for live operation. Another existing gap is that the used components have limited service life.

As for the employees, at first, they have not accepted this solution well. Most of them were afraid of a new technology and refused it. But after a few work cycles with displayed virtual instructions they have found out that this solution saves large amount of time.

The main insight of this research is that this type of virtual solution significantly reduces training time of new employees. The main advantage of this solution is that it can be deployed in a real production line with a relatively simple connection to the production equipment. The device collects a signal from the connected devices and evaluates whether the operator has used the option to move to the next step. Another possible adaptation of the control is the connection to more sensors and the possibility to evaluate which device controls the next step. 
Another significant element will be the enrichment of the manual itself with other elements of visual management, and also sound, as mentioned in [Ardi and Al-Rasyid, 2016]. Overall, this solution will be used on other devices to collect the necessary data to create a universal methodology for displaying certain content connected to the production cycle.

This type of solution can be used in companies with a high turnover rate and a high rate of scrap. The proposed solution can work in a high-cycle environment. This feature means that such a device can be used at almost any production facility.

Another possibility of this research could be to use multiple types of sensors for one type of operation. For example, an optical device that would simultaneously evaluate the type of defect during the animation. The evaluation of this device would be based on artificial intelligence. This function allows the removal of the control station and thus significantly reduces the cost of this workplace. The future direction should include implementation of a cloud server storage to reduce initial costs. Then there will be no need for an extra hardware such as PC. Cloud server will accept the data from PLC devices. Virtual instructions can be displayed on different devices. Those devices will communicate with cloud storage and displayed virtual instructions will interact with the signals from the cloud.

\section{Acknowledgments}

This article was created with the support of an internal grant from the University of West Bohemia SGS-2021-028.

\section{References}

[Abidi 2019] Abidi, M.H., Al-Ahmari, A., Ahmad, A., Ameen, W. Alkhalefah, H., 2019. Assessment of virtual reality-based manufacturing assembly training system. Int. J. Adv. Manuf. Technol. 105, 3743-3759. https://doi.org/10.1007/s00170-01903801-3

[Ardi 2016] Ardi, S., Al-Rasyid, A., 2016. Design of pokayoke sensor systems in drill oil hole machine to detect the presence of drill using programmable logic controller. Adv. Sci. Lett. 22, 18131816. https://doi.org/10.1166/asl.2016.7034

[Blazek 2013] Blazek, J., 2013. Kurzy programovani PLC Siemens Simatic [WWW Document]. URL https://foxon.cz/blog/kurzyprogramovani/kurzy-programovani-simatic-s7-300/182-kurzprogramovani-plc-siemens-simatic-s7-300-dil-1\#tri

[Carlson 2015] Carlson, P., Peters, A., Gilbert, S.B., Vance, J.M., Luse, A., 2015. Virtual Training: Learning Transfer of Assembly Tasks. IEEE Trans. Vis. Comput. Graph. 21, 770-782. https://doi.org/10.1109/TVCG.2015.2393871

[Chen 2017] Chen, J.Y., Tai, K.C., Chen, G.C., 2017. Application of Programmable Logic Controller to Build-up an Intelligent Industry 4.0 Platform. Procedia CIRP 63, 150-155. https://doi.org/10.1016/j.procir.2017.03.116

[Eurostat 2020] EUROSTAT, b.r. Total unemployment rate [WWW Document]

URL https://ec.europa.eu/eurostat/tgm/table.do?tab=table\&init=1\& language $=e n \&$ pcode $=$ tps $00203 \&$ plugin $=1$

[Garcia 2011] Garcia, A.C.B., Bentes, C., de Melo, R.H.C., Zadrozny, B.,
Penna, T.J.P., 2011. Sensor data analysis for equipment monitoring. Knowl. Inf. Syst. 28, 333-364. https://doi.org/10.1007/s10115-010-0365-1

[Guo 2020] Guo, Z., Zhou, D., Zhou, Q., Zhang, X., Geng, J., Zeng, S., Lv, C., Hao, A., 2020. Applications of virtual reality in maintenance during the industrial product lifecycle: A systematic review. J. $\begin{array}{lll}\text { Manuf. Syst. 525-538. } & \text { 56, }\end{array}$ https://doi.org/10.1016/j.jmsy.2020.07.007

[Halbrstat 2018] Halbrstat, J., 2018. Vysoka fluktuace nasobi problemy firem s nedostatkem zamestnancu. Vyplati se hlavne venovat novackum | Hospodarske noviny (iHNed.cz) [WWW Document]. URL https://logistika.ihned.cz/c1-66167040-vysoka-fluktuacenasobi-problemy-firem-s-nedostatkem-zamestnancu-vyplati-sehlavne-venovat-novackum (spotted 10.25.20).

[Horejsi 2019] Horejsi, P., 2019. Vyuziti virtualni a rozsirene reality v prumyslovych podnicich. Zapadoceska univerzita v Plzni.

[Horejsi 2015] Horejsi, P., 2015. Augmented Reality System for Virtual Training of Parts Assembly. Procedia Eng. 100, 699-706. https://doi.org/https://doi.org/10.1016/j.proeng.2015.01.422

[Kana 2021] Kana, S., Tee, K.-P., Campolo, D., 2021. Human-Robot comanipulation during surface tooling: A general framework based on impedance control, haptic rendering and discrete geometry. Robot. Comput. Integr. Manuf. 67, 102033. https://doi.org/https://doi.org/10.1016/j.rcim.2020.102033

[Kiangala 2018] Kiangala, K.S., Wang, Z., 2018. Initiating predictive maintenance for a conveyor motor in a bottling plant using industry 4.0 concepts. Int. J. Adv. Manuf. Technol. 97, 32513271. https://doi.org/10.1007/s00170-018-2093-8

[Maiti 2019] Maiti, A., Maxwell, A.D., Kist, A.A., 2019. Visual Tools for Aiding Remote Control Systems Experiments with Embedded Controllers, in: Auer, M.E., Langmann, R. (Ed.), Smart Industry \& Smart Education. Springer International Publishing, Cham, s. 415-424.

[Novikov 2019] Novikov, K., 2019. Zefektiveni provadeni vyrobnich procesu $\mathrm{v}$ ramci technicke pripravy vyroby. Zapadoceska univerzita v Plzni.

[Patle 2019] Patle, D.S., Manca, D., Nazir, S., Sharma, S., 2019. Operator training simulators in virtual reality environment for process operators: a review. Virtual Real. 23, 293-311. https://doi.org/10.1007/s10055-018-0354-3

[Radianti 2020] Radianti, J., Majchrzak, T.A., Fromm, J., Wohlgenannt, I., 2020. A systematic review of immersive virtual reality applications for higher education: Design elements, lessons learned, and research agenda. Comput. Educ. 147, 103778. https://doi.org/10.1016/j.compedu.2019.103778

[Stratman 2004] Stratman, J.K., Roth, A. V., Gilland, W.G., 2004. The deployment of temporary production operators in assembly operations: A case study of the hidden costs of learning and forgetting. J. Oper. Manag. 21, 689-707. https://doi.org/10.1016/j.jom.2003.11.001

[Urban 2004] Urban, J., 2004. Vykladovy slovnik rizeni lidskych zdroju s anglickymi ekvivalenty. ASPI, Praha. 
[Villalonga 2019] Villalonga, A., Castano, F., Beruvides, G., Haber, R., Strzelczak, S., Kossakowska, J., 2019. Visual analytics framework for condition monitoring in cyber-physical systems, in: 2019 23rd International Conference on System Theory, Control and Computing, ICSTCC 2019 - Proceedings. s. 55-60. https://doi.org/10.1109/ICSTCC.2019.8885611 


\section{CONTACTS:}

Ing. Jan Kubr kubrj@kpv.zcu.cz

University of West Bohemia , Faculty of Mechanical

Engineering, Department of Industrial Engineering and

Management

Univerzitni 8, 30614 Pilsen, Czech Republic

Ing. Konstantin Novikov, MBA novikov@kpv.zcu.cz

University of West Bohemia , Faculty of Mechanical

Engineering, Department of Industrial Engineering and

Management

Univerzitni 8, 30614 Pilsen, Czech Republic

doc. Ing. Petr Horejsi, Ph.D. tucnak@kpv.zcu.cz University of West Bohemia , Faculty of Mechanical Engineering, Department of Industrial Engineering and Management

Univerzitni 8, 30614 Pilsen, Czech Republic

doc. Ing. Jana Kleinova, CSc. kleinova@kpv.zcu.cz University of West Bohemia , Faculty of Mechanical Engineering, Department of Industrial Engineering and Management

Univerzitni 8, 30614 Pilsen, Czech Republic

Ing. David Krakora krakora@kpv.zcu.cz University of West Bohemia, Faculty of Mechanical Engineering, Department of Industrial Engineering and Management

Univerzitni 8, 30614 Pilsen, Czech Republic 